\title{
Concurrent Provision of Frequency Regulation and Overvoltage Support by Electric Vehicles in a Real Danish Low Voltage Network
}

\author{
Knezovic, Katarina; Marinelli, Mattia; Andersen, Peter Bach; Træholt, Chresten
}

Published in:

Proceedings of IEEE International Electric Vehicle Conference 2014

Link to article, DOI:

10.1109/IEVC.2014.7056099

Publication date:

2014

Document Version

Early version, also known as pre-print

Link back to DTU Orbit

Citation (APA):

Knezovic, K., Marinelli, M., Andersen, P. B., \& Træholt, C. (2014). Concurrent Provision of Frequency Regulation and Overvoltage Support by Electric Vehicles in a Real Danish Low Voltage Network. In Proceedings of IEEE International Electric Vehicle Conference 2014 IEEE. https://doi.org/10.1109/IEVC.2014.7056099

\section{General rights}

Copyright and moral rights for the publications made accessible in the public portal are retained by the authors and/or other copyright owners and it is a condition of accessing publications that users recognise and abide by the legal requirements associated with these rights.

- Users may download and print one copy of any publication from the public portal for the purpose of private study or research.

- You may not further distribute the material or use it for any profit-making activity or commercial gain

- You may freely distribute the URL identifying the publication in the public portal 


\title{
Concurrent Provision of Frequency Regulation and Overvoltage Support by Electric Vehicles in a Real Danish Low Voltage Network
}

\author{
Katarina Knezović, Mattia Marinelli, Peter Bach Andersen, Chresten Træholt \\ Department of Electrical Engineering (Center for Electric Power and Energy), DTU - Technical University of Denmark \\ $\{$ kknez, matm, pba, ctr\}@elektro.dtu.dk
}

\begin{abstract}
Expected deployment of electric vehicles (EVs) introduces big technical challenges for power system operation, but also offers advantages provided that EVs are not considered merely as passive loads. With the development of Vehicle-toGrid technology, EVs will be able to provide a number of ancillary services for grid support, e.g. implemented electronic equipment will allow them to exchange reactive power with the grid for voltage regulation while using active power for other services. This paper investigates the concurrent provision of local and system wide services from EVs in a real Danish low voltage network with high penetration of photovoltaic installations (PVs). The main focus is potential reactive power support when EV provision of frequency regulation coincides with PV production. Furthermore, the paper evaluates benefits of overvoltage support and addresses the issue of increased loading. The analysed network has been modelled in Matlab SimPowerSystems and is based on real hourly metered data from a Danish MV/LV substation with numerous households.
\end{abstract}

Index Terms--distribution network, electric vehicles, frequency regulation, photovoltaic, power system modelling, reactive power control, voltage support

\section{INTRODUCTION}

With conventional generating units being replaced by renewable resources, there is an increased demand for additional ancillary services in order to achieve certain frequency and voltage requirements. Growing number of photovoltaic installations in distribution networks highly influences voltage gradients since the production usually coincides with low residential consumption [1], [2]. Therefore, modern solar inverters typically have the capability of providing reactive power control (RPC) by injecting inductive or capacitive reactive power and decreasing voltage deviations [3]. In addition, electric vehicles (EVs) are a viable alternative to traditional vehicles and should not be considered as merely passive loads since development of smart grid enabling technologies and Vehicle-to-Grid enables them to provide numerous services [4]-[7]. Considering they are typically plugged-in $90 \%$ of the time, EVs can contribute to grid support by providing various ancillary services such as frequency [8] and voltage regulation [9]. However, when providing such services, it is necessary to analyse the grid impact, especially in critical situations when the network is already stressed with high

This work is supported by the Danish Project - Nikola - under ForskEL kontrakt nr. 2013-1-12088. penetration of distributed generation, as triggering the need for other services is not desirable [10]. Since EV charging infrastructure enables provision of reactive power for voltage support without affecting battery state-of-charge [11], it can be used simultaneously with other services to mitigate their adverse effects.

This paper analyses the potential of reactive power control from EVs, similar to the one of PV inverters, in a real Danish low voltage distribution network with focus on overvoltages caused by providing frequency regulation in times of high PV production. Furthermore, relevant network parameters such as current and energy losses are evaluated to provide insight into RPC benefits and drawbacks. The rest of the paper develops as follows: Section II reports the used methodology and the simulation model of the observed network, Section III presents and discusses conducted scenarios with their results, and Section IV concludes the potential benefits and drawback of implementing this concept.

\section{METHODOLOGY}

\section{A. Low voltage network}

The analysed real network has been modelled in Matlab SimPowerSystems and illustrates a typical Danish semi-urban low voltage network located in eastern Denmark. This paragraph will briefly describe the network topography, further network details can be found in [9]. The observed 0.42 $\mathrm{kV}$ feeder is radially run and connected to $10 \mathrm{kV}$ medium voltage network through a typical Danish $400 \mathrm{kVA}$ distribution transformer with three-phase short circuit power of 20 MVA. It contains approximately $680 \mathrm{~m}$ of cables in 13 line segments and 43 households in total which are categorized in two groups depending on their location and

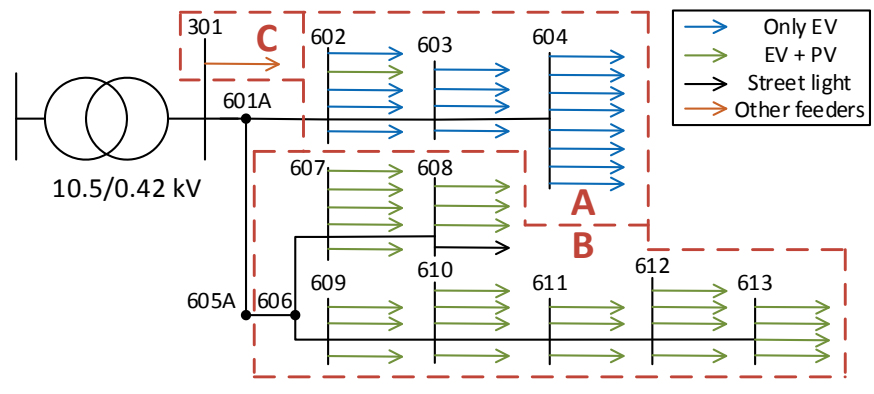

Fig. 1. Analysed low voltage network - single line diagram 
consumption characteristics. There are three additional feeders under the same transformer substation which are represented as a single aggregated household due to lack of data for individual house. Moreover, it is assumed that the voltage at the transformer low-voltage side is kept at 1 p.u.

The single line diagram for the described network is depicted in Fig. 1. All households marked with green contain PV installations in addition to electric vehicles. These are mainly the households located in the Græsmarken Street, i.e. area $\mathrm{B}$. Besides them, there is a street light connected to the grid at node 608 which is marked black. On the other side, area A represents households located in the Hørmarken Street which do not contain PV installations but only electric vehicles. The rest of the consumption and PV production located in the three other feeders under the same transformer is marked brown and highlighted as area $\mathrm{C}$.

\section{B. Household consumption profiles}

As already mentioned, the households are divided in two categories: (1) residential houses in Hørmarken Street with lower consumption during the heating season due to implemented district heating, and (2) residential houses in Græsmarken Street which have heat pumps and consequently higher consumption during the heating period.

Individual consumption profiles are based on real hourly metered data for a period of one year (from March 2012 to March 2013). Even though the modelled network is threephased, there is no insight into individual phase fractions for the measured power flows. Therefore, it is assumed that the loading is equally distributed and symmetrically balanced between the phases. Additionally, the measured data contain only active power component, so a fixed power factor (equal to 0.95 inductive) has been assumed as a reference value for all households.

This paper focuses on overvoltage support in steady-state, so the most interesting period for the analysis is a spring week in mid-May. This week has been chosen due to low consumption and high PV production resulting in the highest net power flow from the feeder to the MV grid in the given year. Fig. 2shows consumption pattern for the observed spring week distinguishing feeder consumption and total transformer consumption, as well as the average daily house profile calculated as a mean of all consumption values at specific hour, separately for Hørmarken and for Græsmarken.

\section{Photovoltaic production profiles}

Photovoltaic installations in the observed feeder are almost entirely located in Græsmarken and are all connected through single phase inverters. However, the connection point of each installation to the individual phase is not known since there is no specific DSO regulation but it depends on the accredited electrician's technical choice. Therefore, the PVs in the model have been randomly connected taking into consideration that overall production per phase is approximately the same. In addition, one single production representing the cumulated PV production from other three feeders has been added to the low voltage side of the

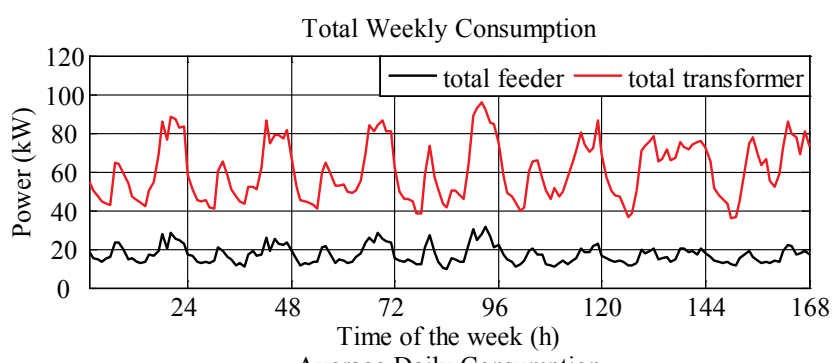

Average Daily Consumption

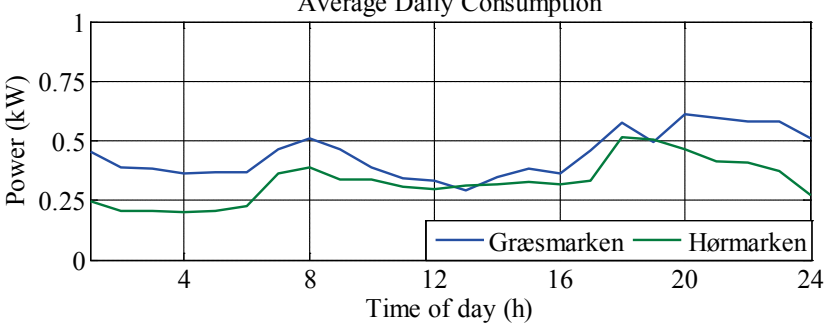

Fig. 2. Total weekly and average daily consumption for the observed week

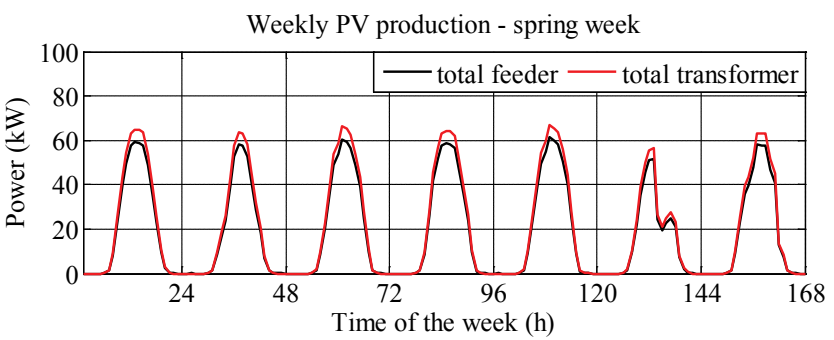

Average daily PV production - spring week

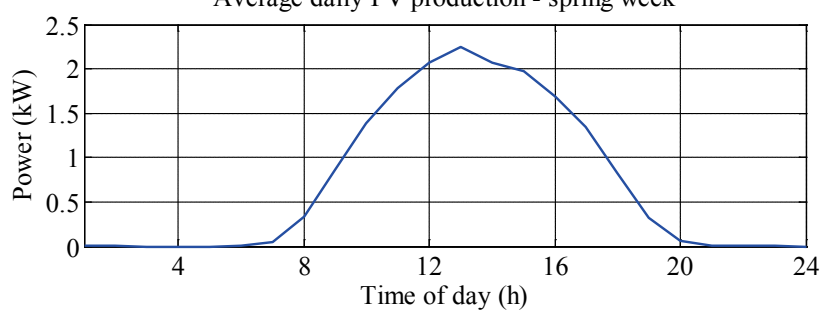

Fig. 3. Total weekly and average daily PV production for the observed week

transformer and has been evenly distributed between the phases.

The modelled feeder contains $27 \mathrm{PV}$ installations in total: 24 installations with peak power $\mathrm{P}=2.96 \mathrm{~kW}_{\mathrm{p}}$ and 3 upgraded installations with $\mathrm{P}=4.07 \mathrm{~kW}_{\mathrm{p}}$ connected respectively through $3.6 \mathrm{~kW}_{\mathrm{p}}$ and $5.4 \mathrm{~kW}_{\mathrm{p}}$ inverters. As well as the consumption profiles, the production profiles are based on hourly metered data for individual household. Fig. 3 shows total production for the observed spring week at the transformer and feeder level as well as the typical bell-curved profile for a single PV. A comparison of total weekly production and average daily production per household is given in Table I for the observed week. The average daily production is calculated alike the average daily consumption on hourly basis and has been summed up for the 24 hour period. The production under the rest of the feeders is quite low as seen by comparing the values in the table, so it can be assumed that only few installations are located in that part of the network. Besides the PV production, Table I also compares EV active power injection values which are explained in following subchapter. 
TABLE I

OVERVIEW OF ACTIVE POWER INJECTION FOR THE OBSERVED SPRING WEEK

\begin{tabular}{|c|c|c|c|}
\hline & $\begin{array}{c}\text { Total weekly on } \\
\text { transformer level } \\
(\mathrm{kWh})\end{array}$ & $\begin{array}{c}\text { Total weekly } \\
\text { on feeder } \\
\text { level }(\mathrm{kWh})\end{array}$ & $\begin{array}{c}\text { Average daily per } \\
\text { unit }(\mathrm{kWh})\end{array}$ \\
\hline PV & 3403.7 & 3096.2 & 17.01 \\
\hline EV & 4204.2 & 4204.2 & 100.1 \\
\hline
\end{tabular}

\section{Electric vehicles}

Every household is equipped with an electric vehicle connected to a random single phase different from the PV connection point. The overall EV distribution per phase is balanced in the feeder. All EVs have the same "dumbcharging" pattern which has been taken from Test-en-EV program that collected real charging data from 184 vehicles in Denmark [16]. Most of the tested EVs had $16 \mathrm{kWh}$ battery resulting in average charging session of $14.3 \mathrm{kWh}$ with average charging time of $5 \mathrm{~h}$ corresponding to approximately $90 \%$ of the full battery. Implemented charging process starts at 18:00 with $3 \mathrm{~kW}$ in the first hour, $3.7 \mathrm{~kW}$ in the following three hours and ending with $0.2 \mathrm{~kW}$ in the last hour. It mostly coincides with evening peak hours meaning that the vehicles are able to provide ancillary services, e.g. frequency control, at other times.

Because a single EV does not have adequate capacity to participate in energy markets, aggregators are required to combine the capacity of many. The aggregator then bids in the appropriate market and dispatches the signal to EVs requiring certain amount of power [12]. Conducted scenarios assume that the TSO requires maximum active power injection from all EVs through the aggregator in order to maintain the frequency stability. This paper analyses the worst case scenario: when providing such a service takes place in times of high PV production and already high voltages. The active power injection for frequency regulation starts at 12:00 and has the same pattern as "dumb-charging", just the opposite direction bearing in mind that $90 \%$ of the battery is discharged while the remaining $10 \%$ is left for emergency situations. Additional variation for the observed week has been conducted for comparison. It differs only in the time of EV active power injection which is moved to the night period starting from midnight as shown in Fig. 4. The charging period in both analyses is out of scope for this analysis since it causes undervoltage issues.

\section{E. Reactive power control}

Single phase PV inverters are equipped with a reactive power control (RPC) capability related to voltage and produced active power. Voltage limits, i.e. $U_{\min }=0.9$ p.u. and $\mathrm{U}_{\max }=1.1$ p.u, are chosen according to the Danish technical regulation for generation facilities with rated current $16 \mathrm{~A}$ per phase or lower [13]. Considering that the regulation does not specify all RPC requirements, the controller has been modified according to the Italian technical standards [14]. The main objective of this control is lowering the voltage by injecting inductive reactive power whenever the active power injection is high. Since both Italy and part of Denmark belong

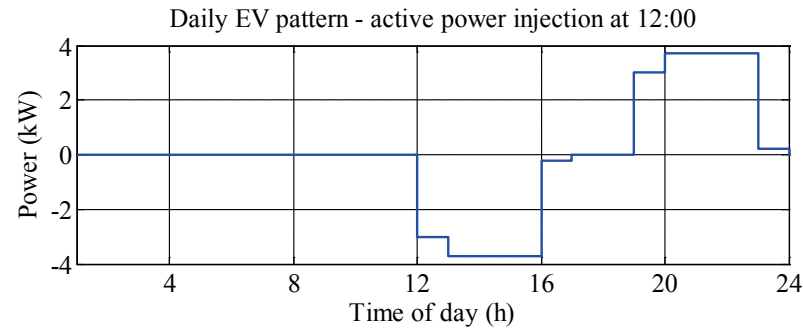

Daily EV pattern - active power injection at 00:00

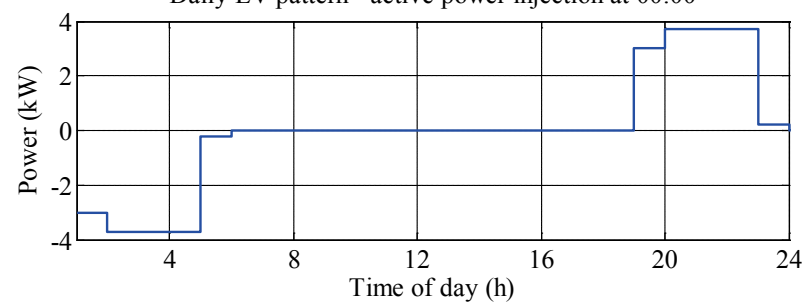

Fig. 4. Daily EV patterns differing in active power injection, i.e. frequency regulation time for the observed week

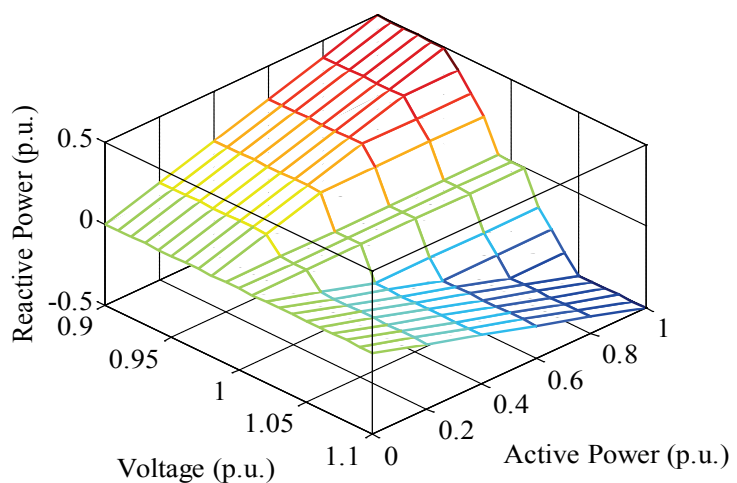

Fig. 5. Reactive Power Control capability for the PV inverters and EV chargers while injecting active power to the grid

to the same synchronous zone, it is reasonable to expect that future Danish requirements will correspond to other European regulations. The implemented RPC function used for these studies is presented in Fig. 5 and has already been used in [9] and [15]. The green range acts as a certain dead band where the controller is active but provides no reactive power, the blue area represents injection of up to 0.5 p.u. inductive reactive power in overvoltage conditions while likewise the red area represents injection of up to 0.5 . p.u. capacitive reactive power in undervoltage conditions.

Since V2G in principle allows both charge/discharge control and inductive/capacitive reactive power control, the described RPC capability was extended to EV chargers assuming they consist of PWM converters. The simplified control scheme for the developed model is given in Fig. 7. As seen from the picture, the controller has three main inputs: active power, voltage and phase shift, while the output is the reference current. Depending on the first two inputs, the controller sets the reactive power according to the described function shown in Fig. 5 or to zero if the RPC activation parameter is off. Afterwards, constant phase shift depending on the device's connection point is added to the apparent power from which the reference current is then calculated. This current is used as the set point for the EV charger. 


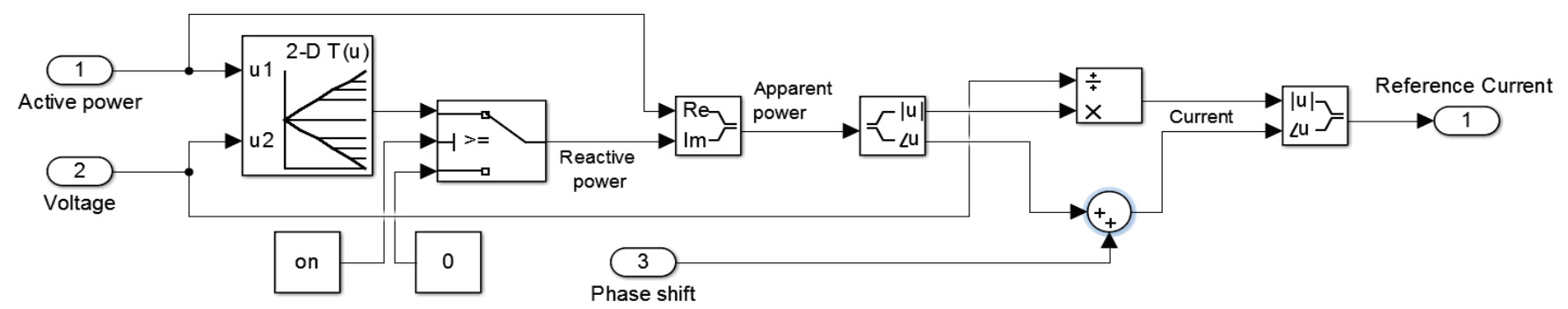

Fig. 7. Simplified Reactive Power Control scheme for PV inverters and EV chargers

\section{F. Scenarios}

This paper compares relevant network parameters such as voltage values, currents and energy losses between different scenarios. Several steady-state analyses listed in Table II have been carried out with results presented in the following section.

All scenarios were conducted in the spring week, but differ with regard to RPC activation as well as to the time of frequency regulation, i.e. active power injection. It is important to note that RPC from PVs does not change through the scenarios, i.e. it is always turned on. Therefore, $\mathrm{PV}$ inverters are always contributing to voltage regulation by injecting inductive reactive power whenever the active power production differs from zero. This can be considered as a base setup to which RPC by EVs has been added and analysed.

TABLE II

SUMMARIZED DETAILS FOR DIFFERENT CONDUCTED SCENARIOS

\begin{tabular}{|c|c|c|c|c|}
\hline Scenario & Season & $\begin{array}{c}\text { Start time of EV active } \\
\text { power injection } \\
\text { (frequency regulation) }\end{array}$ & $\begin{array}{c}\text { RPC by } \\
\text { PVs }\end{array}$ & $\begin{array}{c}\text { RPC by } \\
\text { EVs }\end{array}$ \\
\hline 1 & Spring & $00: 00$ & On & Off \\
\hline 2 & Spring & $00: 00$ & On & On \\
\hline 3 & Spring & $12: 00$ & On & Off \\
\hline 4 & Spring & $12: 00$ & On & On \\
\hline
\end{tabular}

\section{RESULTS}

Since the system is assumed to be balanced, all results are reported using the single phase equivalent. Voltage and current results are depicted via boxplots - a statistical method which divides data in quartiles and indicates dispersion as well as outliers within \pm 1.5 of extreme quartiles $(50 \%$ of data are located within the blue box, upper and lower $25 \%$ are located within the black lines also knows as "whiskers" and outliers are marked with red plus signs). As mentioned before, the results focus on injection periods and disregard charging periods so presented graphs do not include undervoltages occurring in peak periods due to additional load, but instead depict the state as if there were no EVs at those periods for the sake of statistical evaluation.

A. Scenarios with active power injection at 00:00 (scenarios \#1 and \#2)

First two scenarios describe the situation when EVs are providing frequency regulation by injecting active power at midnight. The difference between the scenarios is in RPC

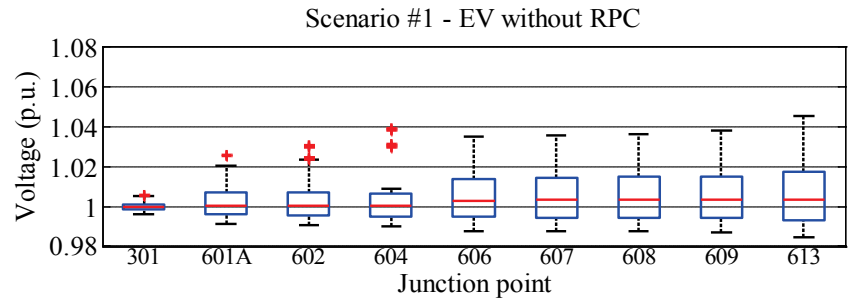

Scenario \#2 - EV with RPC

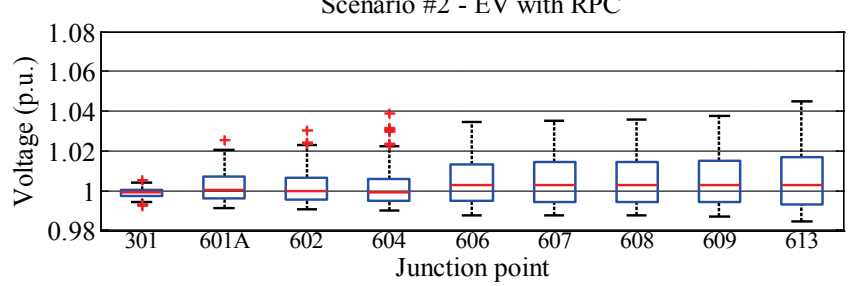

Fig. 6. Voltage comparison for selected junction points in case of EVs injecting active power at 00:00 with and without RPC

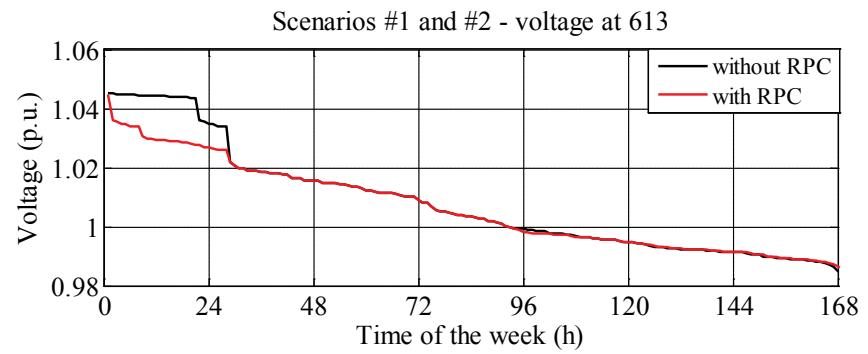

Fig. 8. Voltage magnitude profile at junction point 613 in case of EVs injecting active power at 00:00 with and without RPC

activation; more precisely, while in the first scenario the RPC is turned off, in the second one it is activated and provides voltage support during 5 hours of active power injection.

The results for conducted simulations are given in Fig. 6 where node voltage comparison before and after RPC activation is presented. As it can be seen, maximum voltages along the feeder do not change notably after the RPC activation. This was expected as extremes occur in time of high PV production when there is no voltage support from EVs since they provide frequency regulation during the night. However, even though the maximum value of 1.0453 p.u. is not lowered, RPC lowers the deviation dispersion which can especially be seen at node 604 where most of the outliers have been moved closer to nominal voltage. Moreover, Fig. 8 shows voltage magnitude profile at the end of the line with and without RPC. It can easily be noticed that voltages are lower with RPC. For instance, there was 21 hour in a week with voltages above 1.04 p.u. in case of no RPC while this 
number has been lowered to only 1 hour when RPC was added.

\section{B. Scenarios with active power injection at 12:00 (scenarios \#3 and \#4)}

After studying active power injection during the night, the analysis in case of EVs injecting power at midday was conducted. This can be considered as the worst-case scenario where EV active power injection coincides with PV production causing even higher voltages in the network than already occurring ones.

Obtained voltage results have been reported in Fig. 9 and summarized in Table III. Fig. 9 depicts a three-dimensional representation of the voltage magnitude along the feeder. The $\mathrm{x}$-asis represents time of the week, the $\mathrm{y}$-axis represents the junction points, i.e. feeder nodes, while the voltage values are represented on the z-axis. For an illustration, if one would look at the xz-plane, the voltage profile for a specific feeder node throughout the whole week would be seen. On the other hand, if one would look at the yz-plane, a voltage profile for the whole feeder at a specific point of time could be observed. It is obvious from the figure there are no overvoltages in the observed feeder since the upper technical limit is 1.1 p.u. while the maximum occurring voltage is around 1.06 p.u. in both scenarios. Nonetheless, it is shown that RPC lowers the overall voltages, especially at the end of the feeder. By analysing the results from previous two scenarios, 1.04 p.u. has been taken as a certain voltage threshold, so all the voltages above this limit will be referred to as overvoltages.

Table IV compares number of hours for which the overvoltages appear at each node before and after the RPC activation. For most of the nodes (except for the node 613) the overvoltage hours have been reduced to the order of several hours and for node 604 even to zero. The situation for node 613 is somewhat different and can be seen in Fig. 10 more closely. It is obvious that even though most of the overvoltages are still over 1.04 p.u., they have mainly been lowered, e.g. there are only 6 hours of voltages above 1.05 comparing to 26 hours before the RPC activation.

Keeping in mind that voltage benefits are at the expense of increased cable loading, current analysis has been carried out and presented in Fig. 11 for four specific junction points: transformer low voltage side (node 301), the beginning of the observed feeder (node 601A) and the beginning of each group of households (nodes 602 and 606). First of all, it is important to note how the current at the feeder beginning is higher than the current at the transformer substation level. The reason lies in three other feeders which consume part of the active power injected from EVs. Secondly, the current increase after RPC activation is evident at all nodes due to rise of total reactive power. The active power injection from all EVs is quite high in addition to already existing PV production. Hence, the injected inductive reactive power is high as well in order to maintain the voltages close to 1 p.u. resulting in maximum current increase of almost $38 \mathrm{~A}$ at the beginning of the feeder (node 601A) and higher energy losses as reported later on.
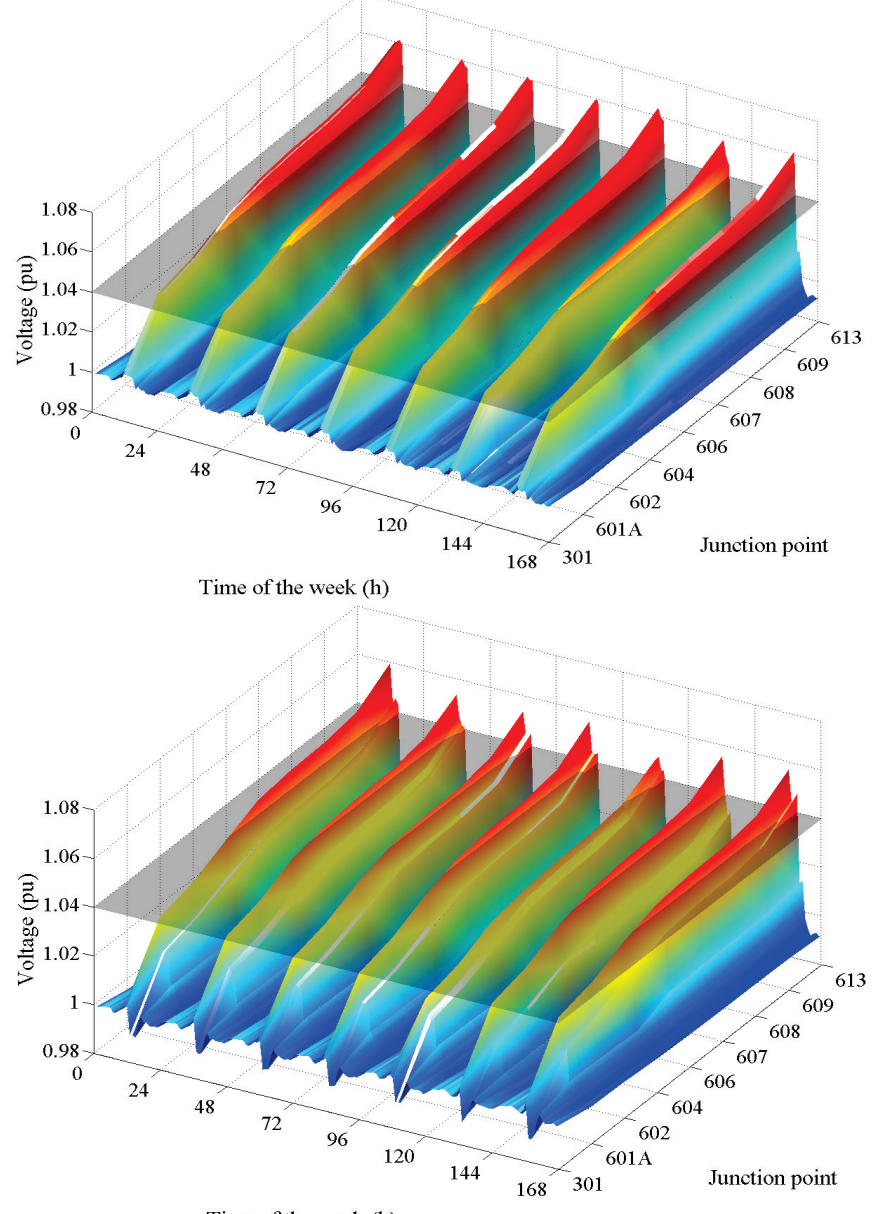

Time of the week (h)

Fig. 9. Voltage magnitude profile along the feeder in case of EVs injecting active power at 12:00 without RPC (upper inset) and with RPC (lower inset)

TABLE III

MAXIMUM VOLTAGES AT SELECTED JUNCTION POINTS BEFORE AND AFTER EV RPC ACTIVATION - SCENARIOS \#3 AND \#4

\begin{tabular}{|c|c|c|c|}
\hline Node & $\begin{array}{c}\text { Maximum voltage } \\
\text { without RPC (p.u.) }\end{array}$ & $\begin{array}{c}\text { Maximum voltage } \\
\text { with RPC (p.u.) }\end{array}$ & $\begin{array}{c}\text { Relative voltage } \\
\text { decrease (\%) }\end{array}$ \\
\hline 301 & 1.0060 & 1.0046 & 0.14 \\
\hline $601 \mathrm{~A}$ & 1.0313 & 1.0289 & 0.23 \\
\hline 602 & 1.0359 & 1.0327 & 0.32 \\
\hline 606 & 1.0489 & 1.0456 & 0.31 \\
\hline 613 & 1.0641 & 1.0597 & 0.42 \\
\hline
\end{tabular}

TABLE IV

NUMBER OF OVERVOLTAGE HOURS BEFORE AND AFTER EV RPC ACTIVATION - SCENARIOS \#3 AND \#4

\begin{tabular}{|c|c|c|}
\hline Node & Overvoltage time without RPC & Overvoltage time with RPC \\
\hline 604 & $22 \mathrm{~h}$ & $0 \mathrm{~h}$ \\
\hline 606 & $27 \mathrm{~h}$ & $6 \mathrm{~h}$ \\
\hline 607 & $27 \mathrm{~h}$ & $6 \mathrm{~h}$ \\
\hline 608 & $27 \mathrm{~h}$ & $6 \mathrm{~h}$ \\
\hline 609 & $28 \mathrm{~h}$ & $6 \mathrm{~h}$ \\
\hline 613 & $29 \mathrm{~h}$ & $26 \mathrm{~h}$ \\
\hline
\end{tabular}




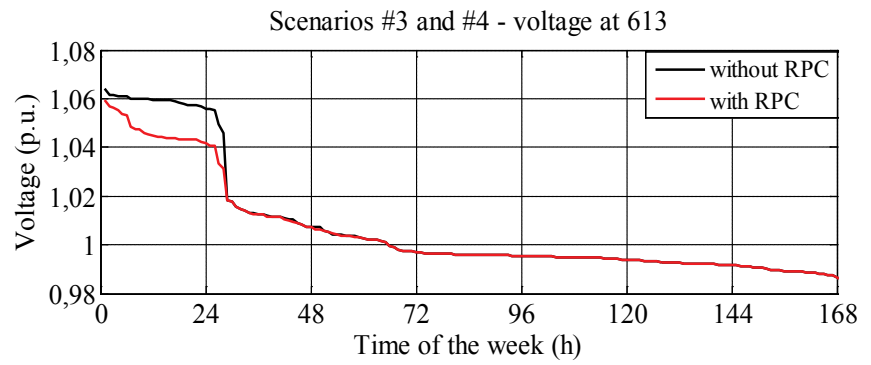

Fig. 10. Voltage magnitude profile at junction point 613 in case of EVs injecting active power at 12:00 with and without RPC
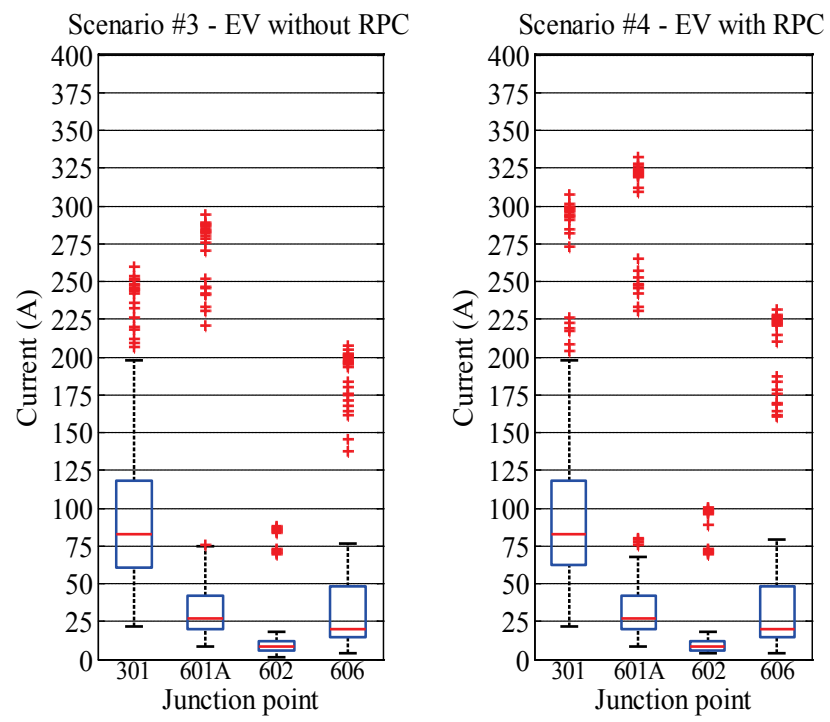

Fig. 11. Current comparison for selected junction points in case of EVs injecting active power at 12:00 with and without RPC

\section{Result overview}

An overview of all presented scenarios is given in Table $\mathrm{V}$ which, besides total absolute active and reactive energy flow without distinguishability of power direction, also reports maximum occurring current and energy losses. Maximum voltage values have not been included since they have been presented before. As it has already been described, the maximum voltage is in neither scenario above the technical requirements which is due to the network topology, more precisely to the relatively long feeder.

For addressing maximum current increase throughout the different scenarios, relative current changes were calculated from reported values. Obtained increase amounted to almost
$29 \mathrm{~A}$ and $38 \mathrm{~A}$, i.e. $14 \%$ and $13 \%$ when activating RPC in scenarios two and four respectively, which is considered to be a high rise. However, even though the total reactive energy has been increased by nearly $40 \%$, the ratio of energy losses and total apparent energy does not change substantially. Comparing the first two scenarios where frequency regulation starts at 00:00, the difference equals to only $0.19 \%$ with maximum deviation of $1.77 \mathrm{kWh} / \mathrm{h}$ while in the case of scenarios three and four, when the provision starts at 12:00, this difference reaches $0.37 \%$ with maximum deviation of 3.2 $\mathrm{kWh} / \mathrm{h}$.

\section{CONCLUSION}

EV integration will highly influence future distribution networks, especially when providing ancillary services to the transmission operator which has no insight in the local network itself. Therefore, when providing such services for the TSO, it is important to maintain voltage requirements in order not to trigger additional ancillary services that the distribution system operator would then need to provide.

This paper presents a case study where concurrent provision of frequency regulation and reactive power control by the EVs was analysed in a real Danish distribution network. Focusing on overvoltage conditions, especially in times when EV active power injection coincides with the PV production, several network parameters such as voltages and energy losses were compared before and after the RPC activation.

The analysis shows that even though the voltages in the network never exceed the upper $+10 \% \mathrm{U}_{\mathrm{n}}$ limit due to relatively long feeders, reactive power control is preferable as it provides smaller voltage deviations. Due to extra reactive power in the grid which reaches up to $40 \%$ increase, excessive cable loading and consequent additional energy losses have also been addressed. It has been noticed that the maximum current had substantially increased with relative change up to $14 \%$ comparing to the scenarios without RPC. Nonetheless, cables and the transformer are not overloaded and relative energy losses have increased only $0.37 \%$ in total leading to conclusion that voltage benefits from RPC activation are greater that the influence on energy losses in the observed distribution network.

Furthermore, presented results assume that the voltage at the transformer low-voltage side is kept at 1 p.u. which may

TABLE V

RESULT OVERVIEW FOR PRESENTED SCENARIOS

\begin{tabular}{|c|c|c|c|c|c|c|c|c|c|}
\hline Case & $\begin{array}{c}\text { Injection } \\
\text { period }\end{array}$ & $\begin{array}{c}\text { RPC } \\
\text { by } \\
\text { EVs }\end{array}$ & $\begin{array}{c}\text { Maximum } \\
\text { current at node } \\
601 \mathrm{~A}(\mathrm{~A})\end{array}$ & $\begin{array}{c}\text { Total absolute } \\
\text { active energy } \\
(\mathrm{kWh})\end{array}$ & $\begin{array}{c}\text { Total absolute } \\
\text { reactive energy } \\
(\mathrm{kVArh})\end{array}$ & $\begin{array}{c}\text { Active } \\
\text { losses } \\
(\mathrm{kWh})\end{array}$ & $\begin{array}{c}\text { Apparent } \\
\text { losses } \\
(\mathrm{kVAh})\end{array}$ & $\begin{array}{c}\text { Ratio of active } \\
\text { losses and total } \\
\text { apparent energy } \\
(\%)\end{array}$ & $\begin{array}{c}\text { Ratio of apparent } \\
\text { losses and total } \\
\text { apparent energy } \\
(\%)\end{array}$ \\
\hline 1 & $00: 00$ & Off & 204.11 & 8640.4 & 3597.2 & 293.87 & 392.95 & 3.01 \\
\hline 2 & $00: 00$ & On & 232.75 & 8668.4 & 5005.4 & 328.07 & 437.07 & 3.16 \\
\hline 3 & $12: 00$ & Off & 294.36 & 11032.0 & 4026.1 & 420.54 & 551.42 & 3.51 \\
\hline 4 & $12: 00$ & On & 332.20 & 11075.0 & 5637.8 & 485.02 & 632.92 & 4.60 \\
\hline
\end{tabular}


not be the case for the whole week. Bearing that in mind and the fact that few PVs have been upgraded to higher power indicating a trend that could expand to other households, it is desirable and maybe even necessary to implement RPC for maintaining the voltages within technical limits.

Although not undertaken in this work, unbalanced phases might also be the limiting factor since most of the PVs and EVs are single-phase connected. Overvoltages appearing on the specific single phase could cause even bigger problems in the network, especially if the EV frequency regulation was provided on the same phase. Therefore, this model will be extended to single phase analysis for further research concerning unbalanced production and to gain insight into network conditions when providing unevenly distributed ancillary services from EVs.

\section{REFERENCES}

[1] K. Knezović and S. Krajcar, "Modelling and Simulating the Impact of a Small Solar Plant to the Low-Voltage Network," EUROCON, 2013 IEEE, pp.1270-1277, Zagreb, July 2013

[2] E. Pasca, G. Petretto, S. Grillo, M. Marinelli and F. Silvestro, "Characterization of wind and solar generation and their influence on distribution network performances," Universities Power Engineering Conference (UPEC), 2009 Proceedings of the 44th International, pp.16, Glasgow, September 2009

[3] E. Demirok, P. C. Gonzales, K. H. B. Frederiksen, D. Sera, P. Rodriguez and R. Teodorescu, "Local Reactive Power Control Methods for Overvoltage Prevention of Distributed Solar Inverters in LowVoltage Grids," Photovoltaics, IEEE Journal of, vol. 1, no. 2, pp. 174 182, October 2011

[4] W. Kempton and J. Tomić, "Vehicle-to-grid power implementation: From stabilizing the grid to supporting large-scale renewable energy," Journal on Power Sources, vol. 144, pp. 280-294, 2005

[5] P. Bach Andersen, M. Marinelli, O. J. Olesen, C. Amtrup, G. Poilasne, B. Christensen, O. Alm, "The Nikola project - Intelligent Electric Vehicle Integration, "Innovative Smart Grid Technologies (ISGT), 2014 IEEE PES, Istanbul, October 2014, in press

[6] F. Marra, D. Sacchetti, A. B. Pedersen, P. B. Andersen, E. Larsen and C. Traeholt, "Implementation of an Electric Vehicle Test Bed Controlled by a Virtual Power Plant for Contributing to Regulating Power reserves," Power and Energy Society General Meeting, IEEE, pp. 1-7., San Diego, July 2012

[7] E. Sortomme and K.W. Cheung, "Intelligent dispatch of Electric Vehicles performing vehicle-to-grid regulation," Electric Vehicle Conference (IEVC), 2012 IEEE International , pp.1-6, Greenville, March 2012

[8] S. Martinenas, M. Marinelli, P. Bach Andersen, C. Træholt, "Implementation and Demonstration of Grid Frequency Support by V2G Enabled Electric Vehicle," Universities Power Engineering Conference (UPEC), 2009 Proceedings of the 49th International, ClujNapoca, September 2014, in press.

[9] K. Knezović, M. Marinelli, R. Juul Møller, P. Bach Andersen, C. Træholt anad F. Sossan, "Analysis of Voltage Support by Electric Vehicles and Photovoltaic in a Real Danish Low Voltage Network," Universities Power Engineering Conference (UPEC), 2009 Proceedings of the 49th International, Cluj-Napoca, September 2014, in press.

[10] H. Hansen, L. H. Hansen, H. Jóhannsson, H. Holm-Hansen, H. W. Bindner, P. Cajar, O. Samuelsson, "Coordination of system needs and provision of services, "Electricity Distribution (CIRED 2013), Electricity Distribution (CIRED 2013), 22nd International Conference and Exhibition on, pp.1-4, June 2013

[11] L. Carradore and R. Turri, "Electric Vehicles participation in distribution network voltage regulation," Universities Power Engineering Conference (UPEC), 2010 45th International, pp.1-6, Cardiff, September 2010
[12] J. Tomic and W. Kempton, "Using fleets of electric-drive vehicles for grid support", Journal of Power Sources, vol. 168, no. 2, pp. 459-468, June 2007

[13] Energinet.dk, "Technical Regulation 3.2.1. for electricity generation facilities with a rated current of 16 A per phase or lower," 2011 (available: http://www.energinet.dk/EN/El/Forskrifter/Technicalregulations/Sider/Regulations-for-grid-connection.aspx)

[14] Italian Technical Standard - CEI 0-21, "Reference technical rules for the connection of active and passive users to the LV electrical Utilities," June 2012. (available: http://www.ceiweb.it/doc/norme/ 12333.pdf)

[15] F. Adinolfi, F. Baccino, M. Marinelli, S. Massucco and F. Silvestro, "Model of a Real Medium Voltage Distribution Network for Analysis of Distributed Generation Penetration in a SmartGrid Scenario," Innovative Smart Grid Technologies (ISGT Europe), 2012 3rd IEEE PES International Conference and Exhibition on, pp.1-7, October 2012

[16] P. Bach Andersen, "Intelligent Electric Vehicle Integration - Domain Interfaces and Supporting Informatics," Ph.D. thesis dissertation, Technical University of Denmark, August 2013 